\title{
Anaesthetic Management of a Patient with Dermatomyositis and Valvular Heart Disease
}

\section{Shrestha GS, Aryal D}

Department of Anaesthesiology

Institute Of Medicine, Tribhuvan University Teaching Hospital, Kathmandu, Nepal

Corresponding Author

Gentle Sunder Shrestha

Department of Anaesthesiology

Institute Of Medicine, Tribhuvan University Teaching Hospital, Maharajgunj, Kathmandu, Nepal

E-mail: gentlesunder@hotmail.com

Citation

Shrestha GS, Aryal D. Anaesthetic Management of a Patient with Dermatomyositis and Valvular Heart Disease. Kathmandu Univ Med J 2012;3(2):100-102.

\begin{abstract}
Dermatomyositis is an idiopathic inflammatory myopathy with involvement of muscle, skin and other organs. Valvular heart disease increases the risk of perioperative adverse cardiac events. Only a little information is available about the anaesthetic management of a patient with dermatomyositis and valvular heart disease. Here we considered combined spinal-epidural technique for total abdominal hysterectomy, minimizing the risk of delayed recovery from muscle relaxants, aspiration pneumonitis, arrhythmias and cardiac failure.
\end{abstract}

\section{KEY WORDS}

Dermatomyositis, valvular heart disease, anaesthetic management

\section{INTRODUCTION}

Dermatomyositis is a multisystem disease of unknown aetiology presenting with characteristic skin changes and muscle weakness. Proximal skeletal muscle groups, especially the flexors of the neck, shoulders and hips are involved. They are at increased risk of pulmonary aspiration and may display abnormal response to muscle relaxants. ${ }^{1}$ There may be pulmonary dysfunction due to weakness of thoracic muscles, interstitial lung disease, or drug-induced pneumonitis. Cardiac disturbances, including atrioventricular conduction defects, tachyarrhythmias, dilated cardiomyopathy, a low ejection fraction, and congestive heart failure, may occur. ${ }^{2}$ Valvular heart disease is not an uncommon finding in patients presenting for noncardiac surgery. ${ }^{3}$ The resulting comorbidities from valvular heart disease significantly increases the risk for perioperative adverse cardiac events in patients undergoing noncardiac surgery. ${ }^{4}$ Only a few case reports are found in literatures regarding anaesthetic management of patients with dermatomyositis and valvular heart disease. Anaesthetic management of such patient needs special considerations.

\section{CASE REPORT}

A 45 years $(72 \mathrm{kgs})$ female presented with diagnosis of fibroid uterus with anaemia due to per vaginal bleeding that increased since previous two weeks. Total abdominal hysterectomy was planned. She was a known case of dermatomyositis. Three years back, she developed dark colouration of skin over face and extensor aspects of hands and feet. It was followed by weakness of the limbs, which was progressive. She needed assistance for standing from squatting position and she also had difficulty combing her hairs. She also had palpitation, dysphagia and features of gastroesophageal reflux and shortness of breath on climbing stairs. Quadriceps muscle biopsy was suggestive 
of dermatomyositis. Since then she was on regular treatment with Prednisolone and Azathioprine. There was good improvement of muscle power with treatment. At presentation, she was anaemic and so transfused with blood. Pulse was irregular and auscultation of precordium revealed systolic murmur, most marked at the apex. Jugular venous pulse was not prominent and there was no pedal oedema. Chest auscultation did not reveal any added sounds. Her motor power in bilateral upper and lower limbs was 4+ out of 5 Medical Research Council scale. Airway assessment was normal. Electrocardiography showed left axis deviation with frequent ventricular premature complexes. Cardiomegaly was obvious in chest radiograph. Echocardiography revealed moderate mitral and aortic regurgitation. Left atrium was dilated and left ventricular ejection fraction was 60 percent. Subserosal fibroid uterus was noted on ultrasonography. Other investigation reports were within normal limits. She was treated with oral Amiodarone and Enalapril.

She was fasted for six hours before surgery. Premedication was done with oral diazepam, ranitidine and metoclopramide. Ampicillin two grams and gentamicin $80 \mathrm{mg}$ was administered intravenously 30 minutes before surgery. Supplemental hydrocortisone $100 \mathrm{mg}$ was given. Intraoperative monitoring included electrocardiography, pulse oxymetry, urine output, invasive arterial blood pressure and central venous pressure. Under all aseptic precautions, epidural catheter was inserted in lumbar 1-2 space and test dose of $3 \mathrm{ml} 2 \%$ lignocaine with adrenaline ( 1 in 200000 dilutions) was given after negative aspiration. It was followed by subarachnoid injection of $2.5 \mathrm{ml} 0.5 \%$ hyperbaric bupivacaine in lumbar 2-3 space. Sensory block of upto tenth thoracic dermatome was attained. Epidural anaesthesia was supplemented with total $10 \mathrm{ml}$ of $2 \%$ lignocaine in increments of $5 \mathrm{ml}$ every five minutes. Finally, sensory block of upto fourth thoracic dermatome was achieved and surgery was started. There was no event of intraoperative hypotension, bradycardia, arrhythmia or desaturation. Post operative analgesia was provided using $0.1 \%$ bupivacaine combined with $3 \mathrm{mg}$ morphine (total $10 \mathrm{ml}$ ) administered through epidural catheter 12 hourly. Her post operative Visual Analogue Scale (VAS) score was less than 4 and there were no events of hypotension and respiratory depression. Post operative course was uneventful, epidural catheter was removed on second post operative day and patient was discharged home on fourth post operative day.

\section{DISCUSSION}

Dermatomyositis is a chronic inflammatory disease with primary involvement of muscles and skin. There is insiduous symmetrical weakness of limb girdles and anterior neck flexors. There may be severe invlovement of muscles of deglutition and respiration. These patients are believed to be sensitive to nondepolatizing muscle relaxants and use of their antagonist drugs may cause muscle weakness and dysrhythmias. ${ }^{5}$ Succinylcholine should be avoided in these patients as it might trigger malignant hyperthermia and may lead to hyperkalemia. ${ }^{6}$ So, while anaesthetizing the patients with inflammmatory myopathy, there is risk of enhanced or delayed effect of neuromuscular blocking agents, aspiration pneumonia, cardiomyopathy with arrhythmias and heart failure, pituitary adrenal axis suppression due to chronic steroid intake, skeletal deformity with resitricted mobility of temporomandibular joint and cervical spine, hyperkalemia and imparied thermoregulation..$^{7-9}$ Regional anaesthesia was found to be safe for caesaren section in a pregnant woman with inflammatory myopathy. ${ }^{10}$

Patients with regurgitant valvular lesions like mitral and aortic regurgitation tolerate regional anaesthetic techniques well with the goal to maintain high heart rate and low afterload. ${ }^{11}$ There is a growing use of regional techniques in high risk cardio-respiratory patients undergoing cesarean section since increasing number of case reports demonstrate satisfactory cardio-vascular stability in these high risk patients. Low dose combined spinal-epidural technique combines the reliability of intrathecal blockade with flexibility of epidural catheter to deliver a titrable and caridovascularly stable anaesthesia with provision of postoperative analgesia. ${ }^{12}$ This technique was shown to be safe, effective and reliable with stable hemodynamics when compared with spinal anaesthesia for high risk geriatric patients undergoing major orthopaedic surgery. ${ }^{13}$ Similarly, combined spinal epidural technique was found to provide superior analgesia and surgical conditions when compared with epidural tecnhique alone in another study enrolling patients undergoing major orthopaedic surgery. ${ }^{14}$

So, in this patient, low dose combined spinal epidural technique was chosen to avoid the use of muscle relaxants, minimize the risk of aspiration pneumonia and with anticipation of a stable hemodynamics. Ranitidine and metoclopramide was administered to minimize the risk of pulmonary aspiration. Hydrocortisone was supplemented since there was the possiblity of pituitary adrenal axis suppression due to long term steroid intake. Epidural analgesia was continued in the post operative period to attain a good pain control.

To conclude, combined spinal-epidural technique can be safe and effective for surgical anaesthesia and post operative analgesia in patients with dermatomyositis and valvular heart disease. Larger case series may better justify the safety and efficacy of this technique.

\section{REFERENCES}

1. Schwartz JJ. Skin and musculoskeletal diseases. In: Hines RL, Marschall KE, editors. Stoelting's Anesthesia and Co-existing Disease. 5th ed. Philadelphia: Churchill Livingstone; 2008. p. 437-67.

2. Dalakas MC. Polymyositis, dermatomyositis, and inclusion body myositis. In: Fauci AS, Braunwald E, Kasper DL, Hauser SL, Longo DL, Jameson JL, et al., editors. Harrison's principles of internal medicine. 17th ed. United States of America: McGraw-Hill; 2008. p. 2696-702. 
3. Nkomo VT, Gardin JM, Skelton TN, Gottdiener JS, Scott CG, EnriquezSarano M. Burden of valvular heart disease: a population-based study. Lancet. 2006; 368: 1005-11.

4. Davenport DL, Ferraris VA, Hosokawa P, Henderson WG, Khuri SF, Mentzer RM. Multivariable predictors of postoperative cardiac events after general and vascular surgery: results from the patient safety in surgery study. J Am Coll Surg. 2007; 204: 1199-1210.

5. Shikha S, Lakshmi J, Nitin S, Jayashree S. Anaesthetic management for laparoscopic cholecystectomy in two patients with biopsy proven polymyositis. Indian J Anaesth. 2007; 51: 43-46.

6. Johns RA, Flinholt DA, Stirt JA. Anesthetic management of a child with dermatomyositis. Can Anaesth Soc J. 1986; 33(1): 71-4.

7. Fujita A, Okutani R, Fu K. Anesthetic management for colon resection in a patient with polymyositis. Masui. 1996; 45(3): 334-36.

8. Makino $M$, Oono $M$, Oosugi $S$, Kamiya $H$, Nakamura $E$, Morimoto $S$. Two cases of polymyositis with cardiac involvement. J Cardiol. 1994; 24(4): 327-34.

9. Fathi M, Lundberg IE, Tronling G. Pulmonary complications of polymyositis and dermatomyositis. Semin Respir Crit Care Med. 2007; 28: 451-458.
10. Gunusen I, Karaman S, Nemli S, Firat V. Anesthetic management for cesarean delivery in a pregnant woman with polymyositis: A case report and review of literature. Case Journal. 2009; 2: 9107.

11. Mittnacht AJC, Fanshawe M, Konstadt S. Anesthetic considerations in the patient with valvular heart disease undergoing noncardiac surgery. Semin Cardiothoracic Vasc Anesth; 12: 33-59.

12. Hamlyn EA, Douglass CA, Plaat F, Crowhurst JA, Stocks GM. Low-dose sequential combined spinal-epidural: an anaesthetic technique for caesarean section in patients with significant cardiac disease. Int J Obstet Anesth. 2005; 14: 355-361.

13. Bhattacharya D, Tewari I, Chowdhuri S. Comparative study of sequential combined spinal epidural anaesthesia versus spinal anaesthesia in high risk geriatric patients for major orthopaedic surgery. Indian J Anaesth. 2007; 51(1): 32-36.

14. Holmstrom B, Laugaland K, Rawal N, Hallberg S. Combined spinal epidural block versus spinal and epidural block for orthopaedic surgery. Can J Anaesth. 1993; 40(7): 601-6. 